\title{
First Trimester
}

\section{${ }^{1} \mathrm{~F}$ Bonilla-Musoles, ${ }^{2} \mathrm{MJ}$ Esquembre, ${ }^{3} \mathrm{~F}$ Bonilla Jr, ${ }^{4} \mathrm{~F}$ Raga, ${ }^{5} \mathrm{JC}$ Castillo, ${ }^{6} \mathrm{LE}$ Machado, ${ }^{7} \mathrm{O}$ Caballero}

\section{ABSTRACT}

This article shows week by week the embryonic and fetal images appeared during the development using HDlive.

We show in this chapter different images of normal and pathological fetuses till the 14th gestational week. As said before, HDlive improves image quality compared to 3D/4D.

Keywords: Normal, Pathologic first trimester pregnancy, Three-dimensional/Four-dimensional, HDlive.

How to cite this article: Bonilla-Musoles F, Esquembre $\mathrm{MJ}$, Bonilla F Jr, Raga F, Castillo JC, Machado LE, Caballero O. First Trimester. Donald School J Ultrasound Obstet Gynecol 2014;8(3):239-249.

\section{Source of support: Nil}

\section{Conflict of interest: None}

\section{INTRODUCTION}

Due to the huge development of the new ultrasound (US) modes appeared in the last 10 years, prenatal diagnosis has experienced a big change. ${ }^{1,2}$

We have increased not only our knowledge about fetus development, but also we have improved the diagnosis of a great quantity of subtle but important and/or complex malformations (low ears implantation, absence of nose bone, etc.).

For instance, by using 3D/4D US, early development of different structures can be better observed (e.g. nervous system) as well as deep or superficial malformations with a great impact in the future. ${ }^{3-6}$

In this way, image quality is extremely important to delineate the origin and extension of these congenital anomalies. In fact, better than 3D/4D US, HDlive contributes and will contribute to allow a better and earlier diagnosis. ${ }^{7}$

Besides, recently introduction of high-resolution endovaginal 3D/4D US has improved the evaluation of fetal morphology, something incredible only 2 years ago. ${ }^{8-22}$

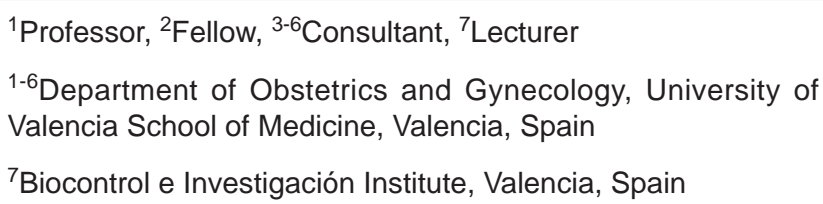

Corresponding Author: F Bonilla-Musoles, Professor Department of Obstetrics and Gynecology, University of Valencia School of Medicine, Avenida Blasco Ibáňez 17, 46011 Valencia Spain, e-mail: profesorbonillamusoles@hotmail.com
What this chapter intends to is to show how image quality improves when using HDlive compared to 3D/4D US while fetal structures appear along first gestational weeks.

Without question, the measurement of the crown-rump length is the fundament for dating correctly gestational age. This measurement is considered nowadays the best way (better than the one referred to the last day of menstruation) to calculate gestational age. Despite this, we also recommend to use the 'embryonic ultrasound timetable' (visualization of different embryologic structures by US). ${ }^{1,7}$

And finally, because of the great image quality HDlive provides of the fetal face, it is used (as 3D US when it appeared) for evaluating not only fetal behavior but also fetal expressions. ${ }^{14-17}$

\section{NORMAL PREGNANCY}

\section{Ultrasound Visualization at 4 to 5 Weeks of Gestation}

At the very beginning of the pregnancy what we see by US is:

- Persistence of vascular activity of the corpus luteum beyond day 21 of the cycle.

- Persistence of a secretory/decidual endometrium beyond day 21 of the cycle.

Neither of these two images is pathognomonic of gestation. They only indicate that pregnancy could be possible.

They are pathognomonic:

- Visualization of the gestational sac. It is a round or oval structure, eco negative and sharply delimited by a thin refractive white ring (because of the trophectoderm). It is surrounded by a second ring, bigger, grayer and thicker. Decidual ring is usually more than $5 \mathrm{~mm}$ (Fig. 1). It grows at a rate of $1.15 \mathrm{~mm}$ daily. This image is often seen by day 31 of amenorrhea.

- Approximately 24 hours later, at day 32, appears inside the sac the yolk sac. It is a small round shaped and very limited ring. Although it is not the first embryonic structure (embryonic button is earlier), it is the first one that can be observed because of its bigger size (Fig. 2).

Its growth rate is slow, a millimeter per week, and when it reaches $7 \mathrm{~mm}$ in week 10, it stops and joins extracoelomic mesenchyme. Although some people say that it is an adnexal structure, it really comes from the transformation of the primary yolk sac (blastocyst cavity) in secondary. 

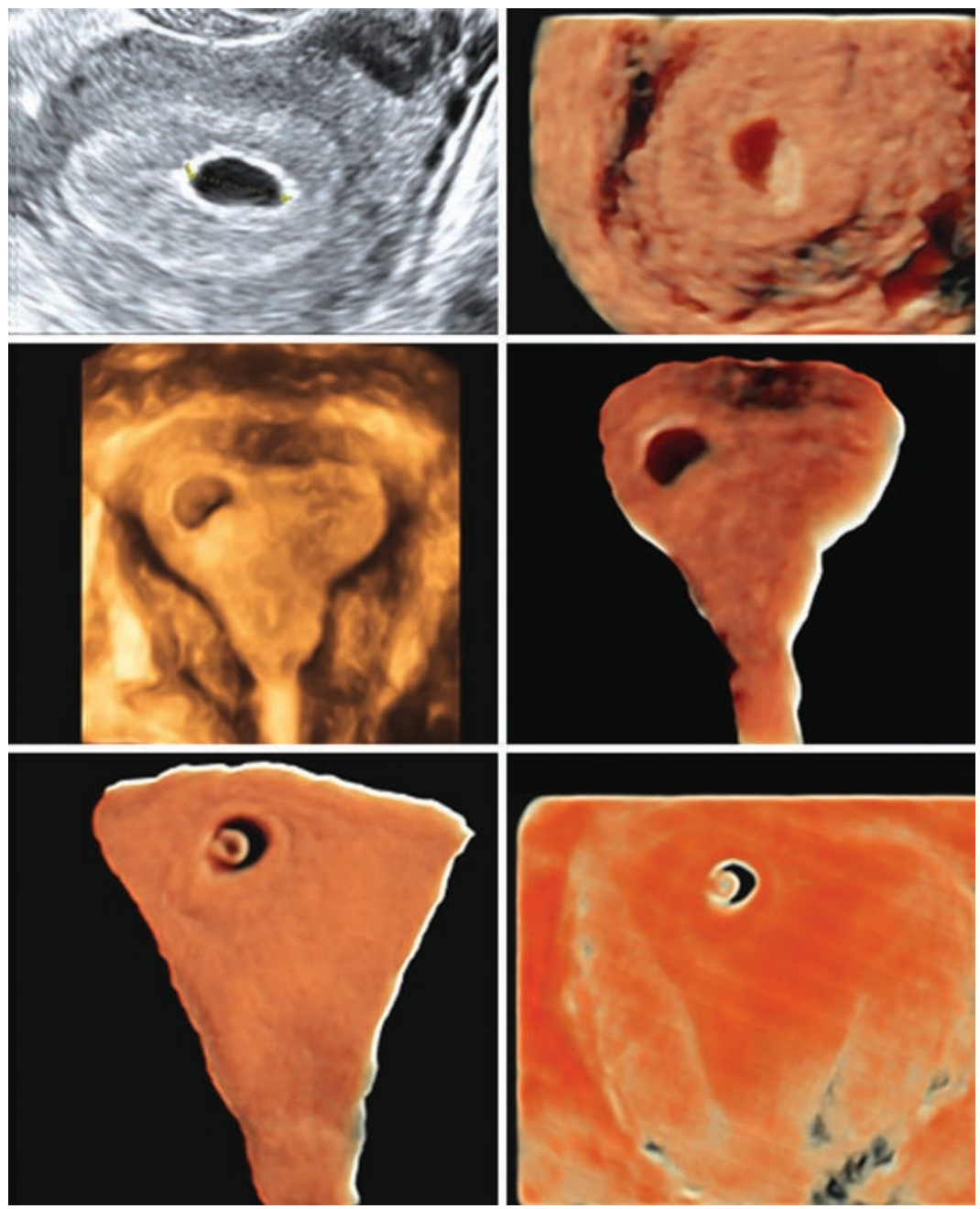

Fig. 1: Very early pregnancies. First two images show a gestational sac with $2 \mathrm{D}$ and HDlive. The third and the fourth ones, show another sac recently implanted near the tubal ostium. Last images show the gestational and yolk sacs with HDlive in its maximum translucency

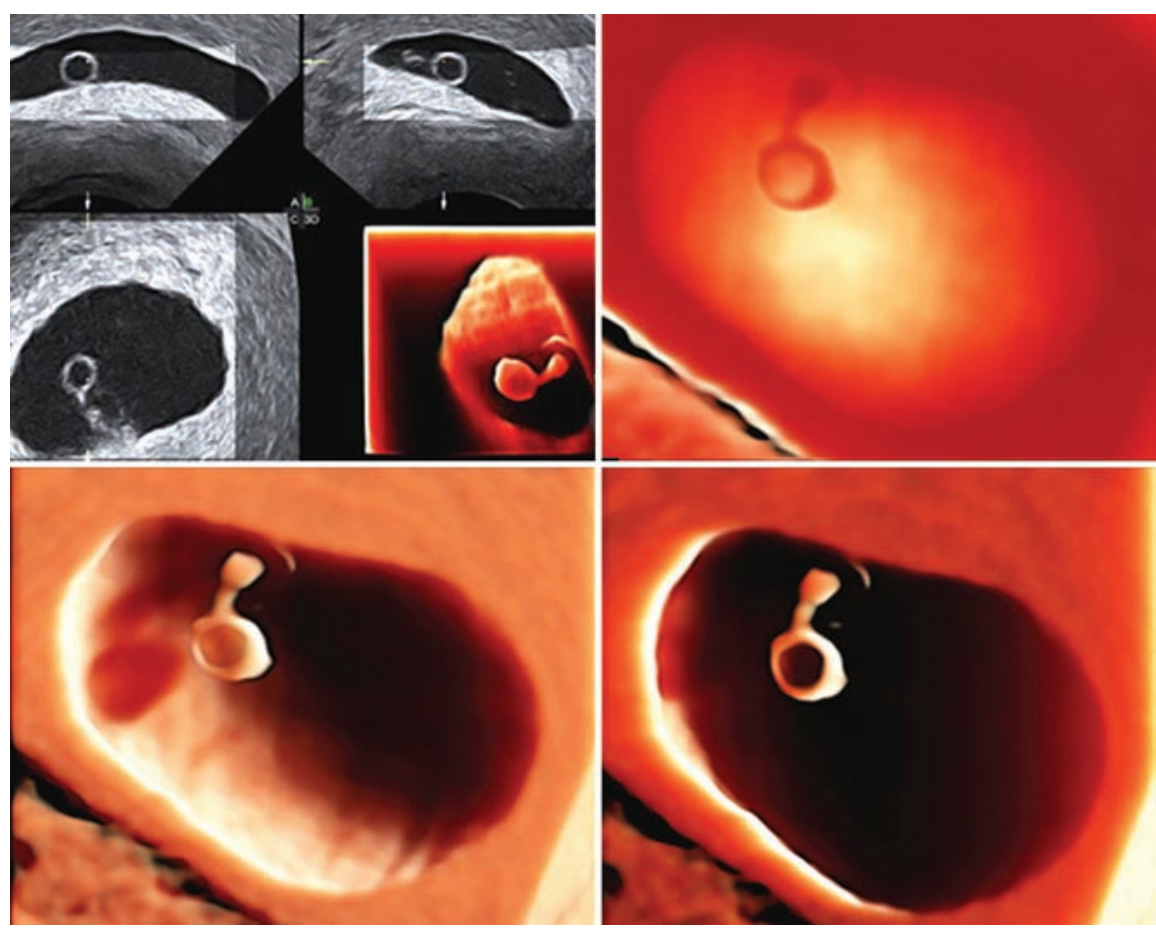

Fig. 2: The image shows a 24-48 hours more advanced gestation than Figure 1. Yolk sac attached to the embryo by the duct omphalo is observed. We compare the 2D with the 3D in orthogonal planes, HDlive and maximum transillumination. The photos have an extraordinary beauty 

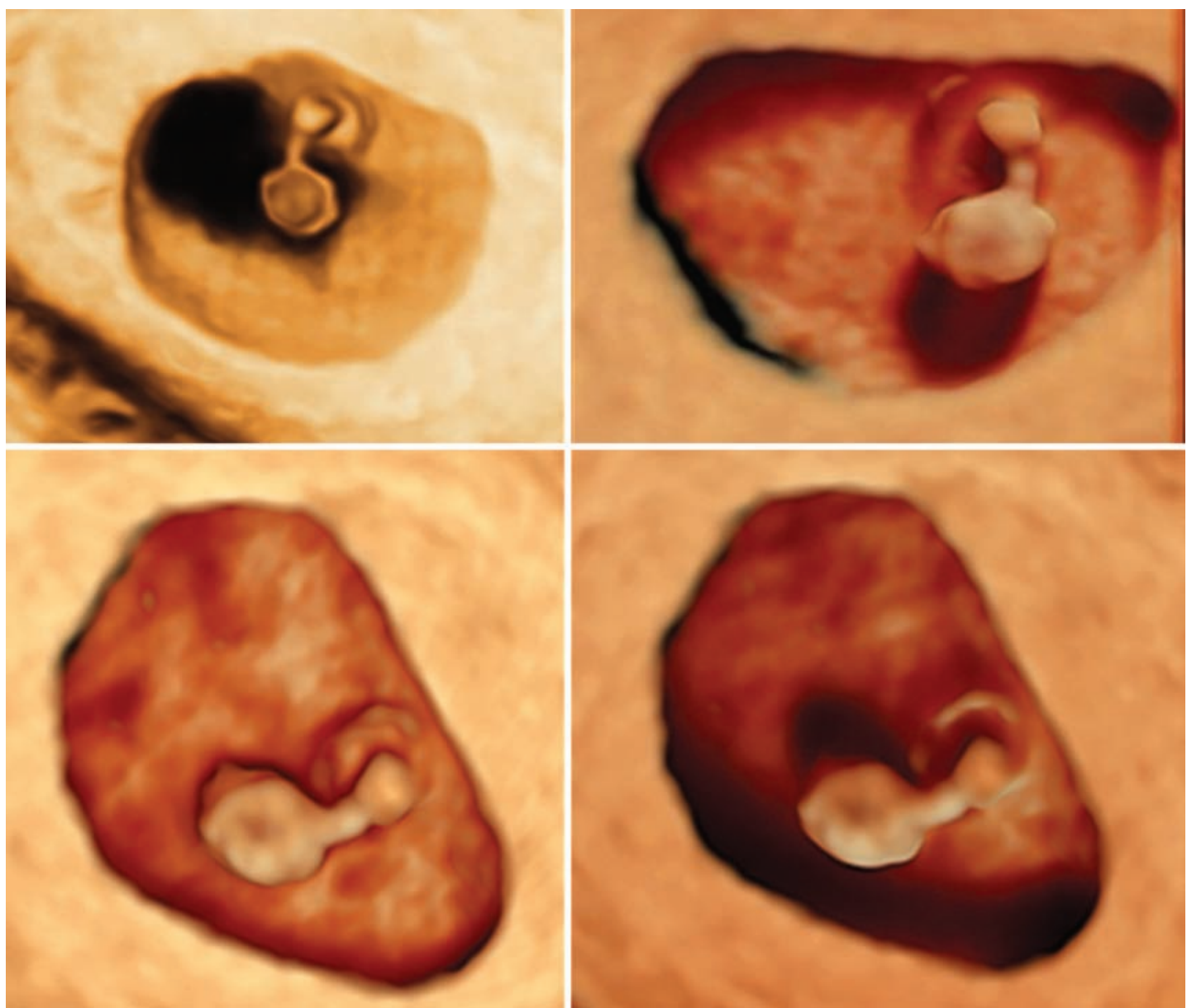

Fig. 3: Three-dimensional (at the left top) and HDlive of a 34-35 days gestation. We show the embryo, only $3 \mathrm{~mm}$, attached by a short omphalomesenteric duct to the yolk vesicle
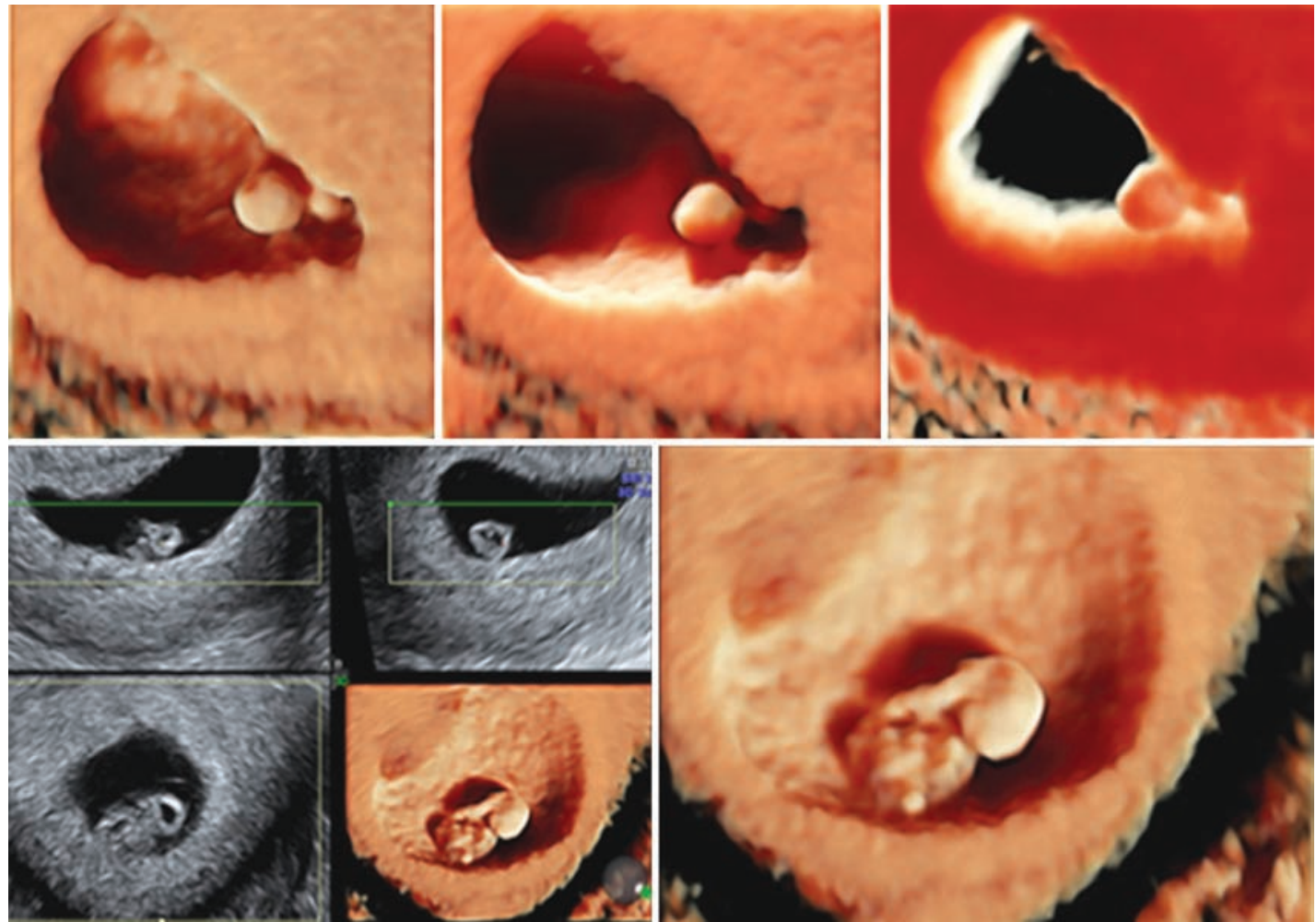

Fig. 4: A pregnancy at the beginning of week 5 (the 3 top images) and the same pregnancy at the end of the same week. At the top of the image, the yolk vesicle and a small embryo of $3 \mathrm{~mm}$ (a white structure) can be seen. In the images below, a large omphalomesenteric duct and a larger embryo can be seen as well 
It has very important functions during the first weeks of pregnancy, for instance:

- It is the place where the first embryo vascularization is made.

- It controls the metabolism and the fetus-maternal transport.

- It produces the closure of the abdominal wall at 11-12 weeks of gestation.

- It controls all the immunity process.

- It creates the amniotic superficial tension.

- 24 hours lately, approximately at day 33 of amenorrhea, the embryo is evident. It appears as a small, well-defined structure, smaller than the yolk vesicle one. It becomes visible when it reaches $2-3 \mathrm{~mm}$. Its growth is very fast, $1.15 \mathrm{~mm} /$ day, while the yolk sac grows much more slowly. Because of that, in only a few days the embryo exceeds the size of the vesicle (Fig. 3).

Within a few hours, the embryo separates from the yolk sac by lengthening the omphalomesenteric duct. This duct becomes very long and can develop cysts on its way, some of them linked to chromosomal abnormalities.

- At the end of the 5 th week or at the beginning of the 6 th one, the beginning of the heartbeat can be seen due to the beating of the two heart-embryo tubes.

\section{Ultrasound Visualization at 6 Weeks of Gestation}

In this week:

- The embryo lengthens itself, it is coma shaped and is bigger than the yolk vesicle.

- It presents two poles, the cephalic or cranial one and the caudal one.

- In the other portion of the embryo, where the omphalomesenteric duct insertion is observed, the amnion is born from the amniotic cavity. Initially, it surrounds the back of the embryo, but in a few hours it surrounds it completely resulting in the 'cavity or amniotic sac' (Figs 4 and 5).

\section{Ultrasound Visualization at 7 Weeks of Gestation}

Apart from the fact that the embryo size is much larger, what can be seen by naked eye or by measuring the crown-rump length, what we see is that the embryo is completely covered by the amnion, swimming in the amniotic fluid, while the yolk sac is outside the extracoelomic mesenchyme.

The most characteristic feature in the $3 \mathrm{D}$ vision is the appearance of:

- The limb buds. Is characteristic to see how the limbs move. Sudden and rapid movements as well as slow or lazy ones can be seen.

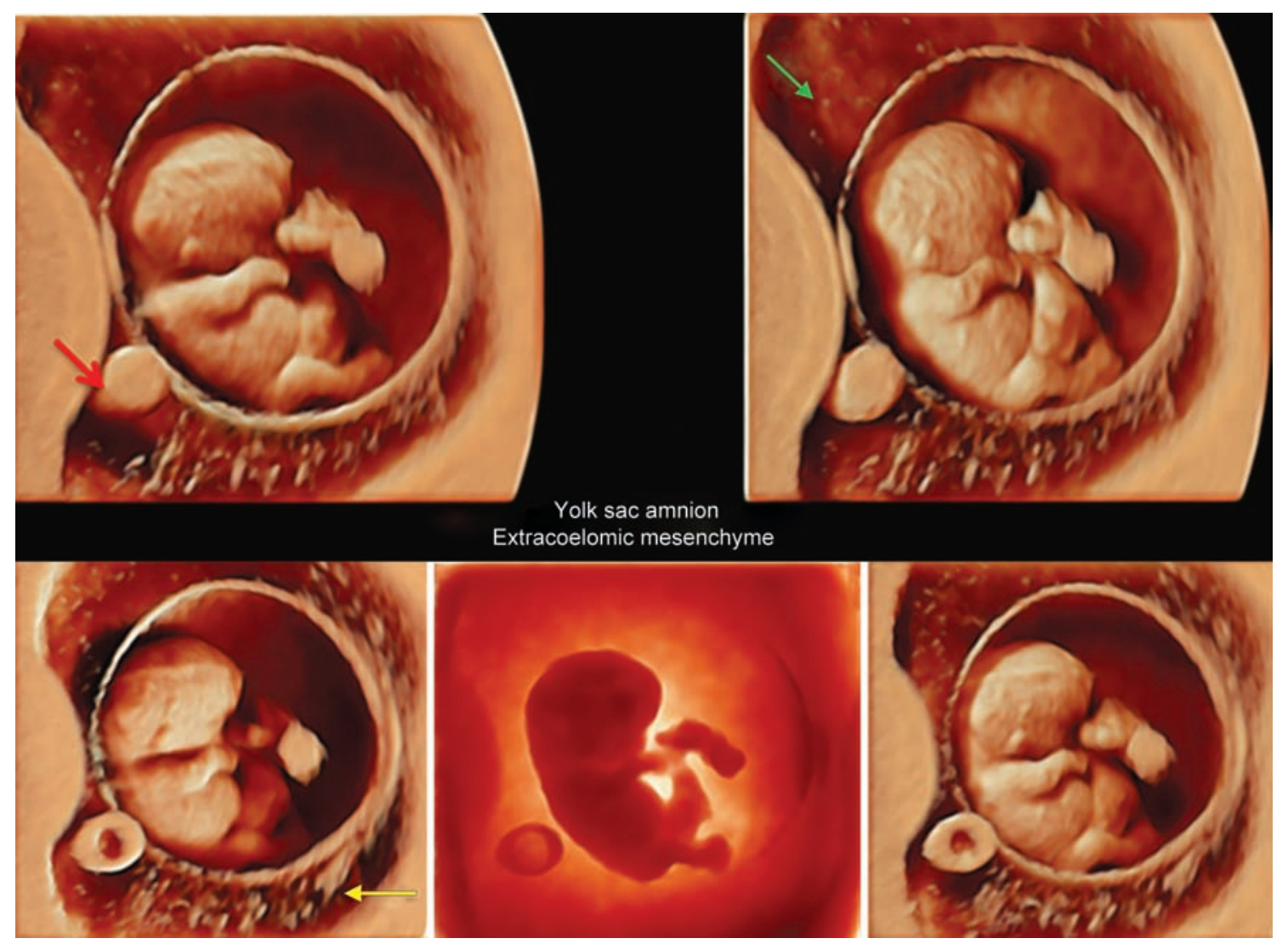

Fig. 5: Pregnancy of 8 weeks and 5 days that we show in order to see the full amnion (green arrow), the embryo in the amniotic cavity, the yolk sac (that is already out and located in the extraembryonic mesenchyme) (red arrow) and the mesenchyme, which is an edematous tissue which appears striped (yellow arrow) 


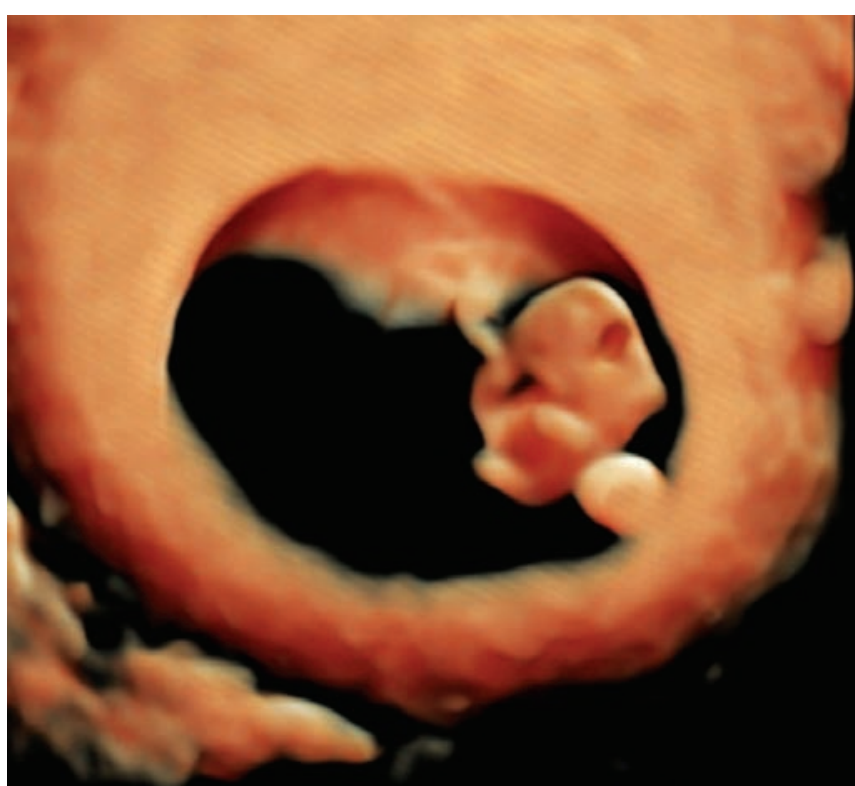

Fig. 6: Eight weeks gestation. In the cranial pole, we see how the hindbrain appears as a small cavity. The entire umbilical cord reaches the placenta
- The neural tube.

- The hindbrain appears at the cranial pole as a cavity (Fig.6).

\section{Ultrasound Visualization at 8 Weeks of Gestation}

- Complete development of limbs, hands and feet can be seen, but fingers are not visible yet. Movements are already present.

- Face is outlined. CNS is completely formed.

- Physiological herniation at the base of the cord appears. It is round, oval or flat, with a maximum size of $7.5 \mathrm{~mm}$. It is a gray and homogeneous echo that disappears at week 12 (Figs 5 to 7).

\section{Ultrasound Visualization at 9 Weeks of Gestation}

- The most important difference is the elongation and the enlargement of the embryo. Limb buds are perfectly defined.

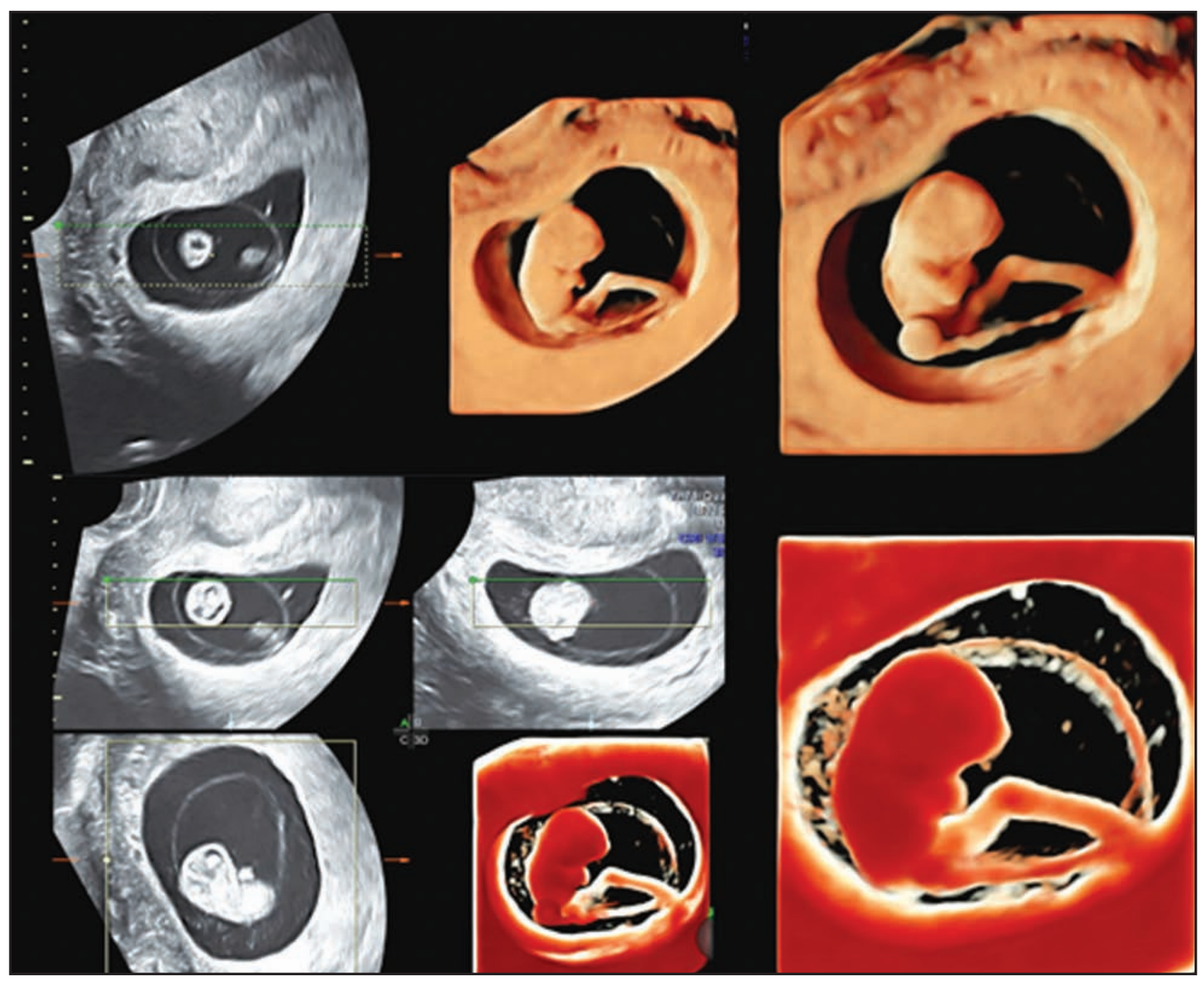

Fig. 7: Eight weeks gestation with HDlive compared to 2D US. Lateral vision of the embryo completely surrounded by the amnion. Cranial and caudal poles, limb buds and umbilical cord can be seen. A very large omphalomesenteric duct that reaches the yolk vesicle, outside the amnion sac, can be seen as well 

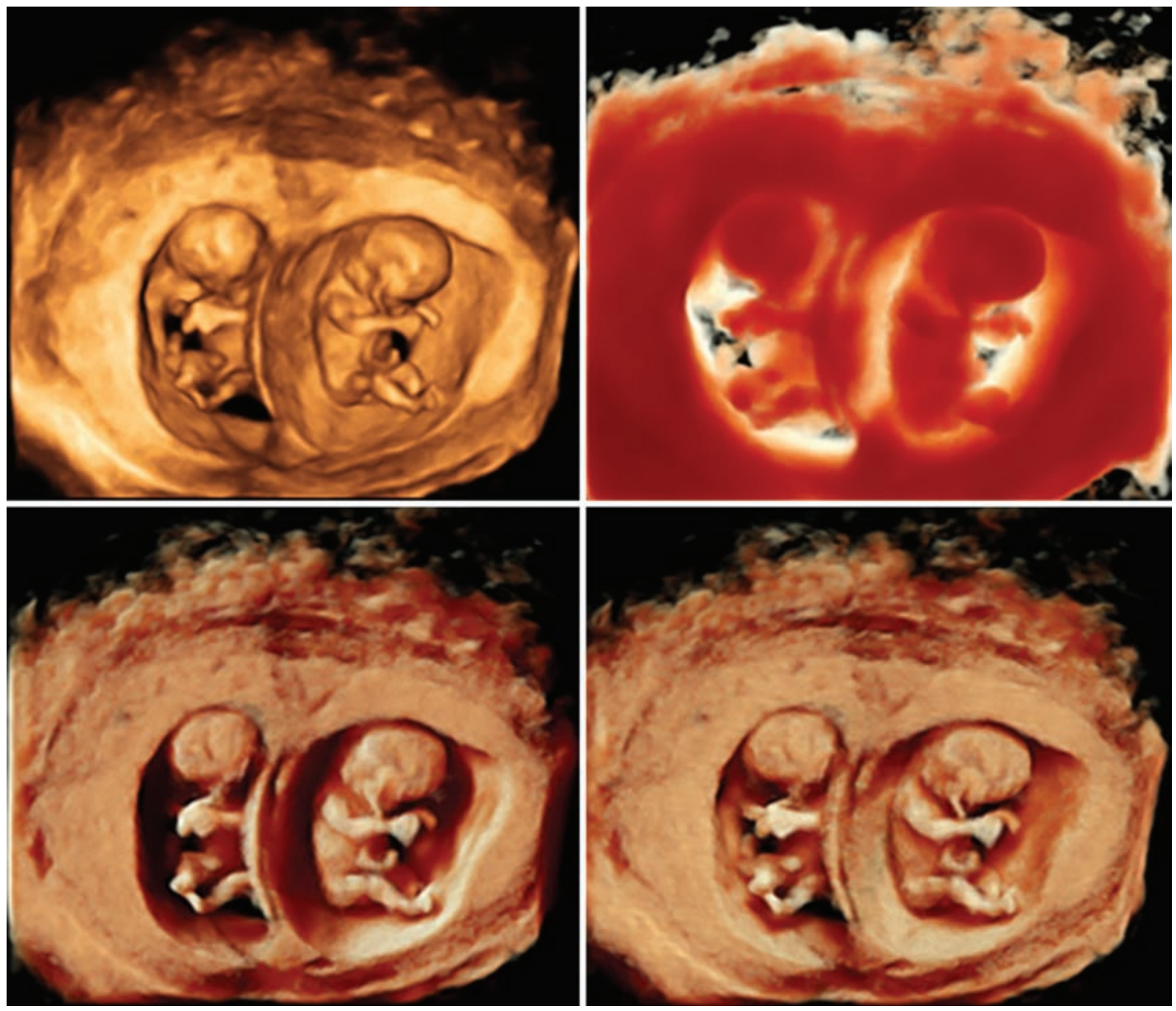

Fig. 8: We show a twin pregnancy of 10 weeks by using different directions of the light source. Superb image resolution of both of the fetus (profile, face, ears, eyes, abdomen, members) the amnion, yolk sac and extraembryonic mesenchyme is obtained. We see all these structures with high luminescence. Note the clarity of the images in order to see the two placentas and the two sacs
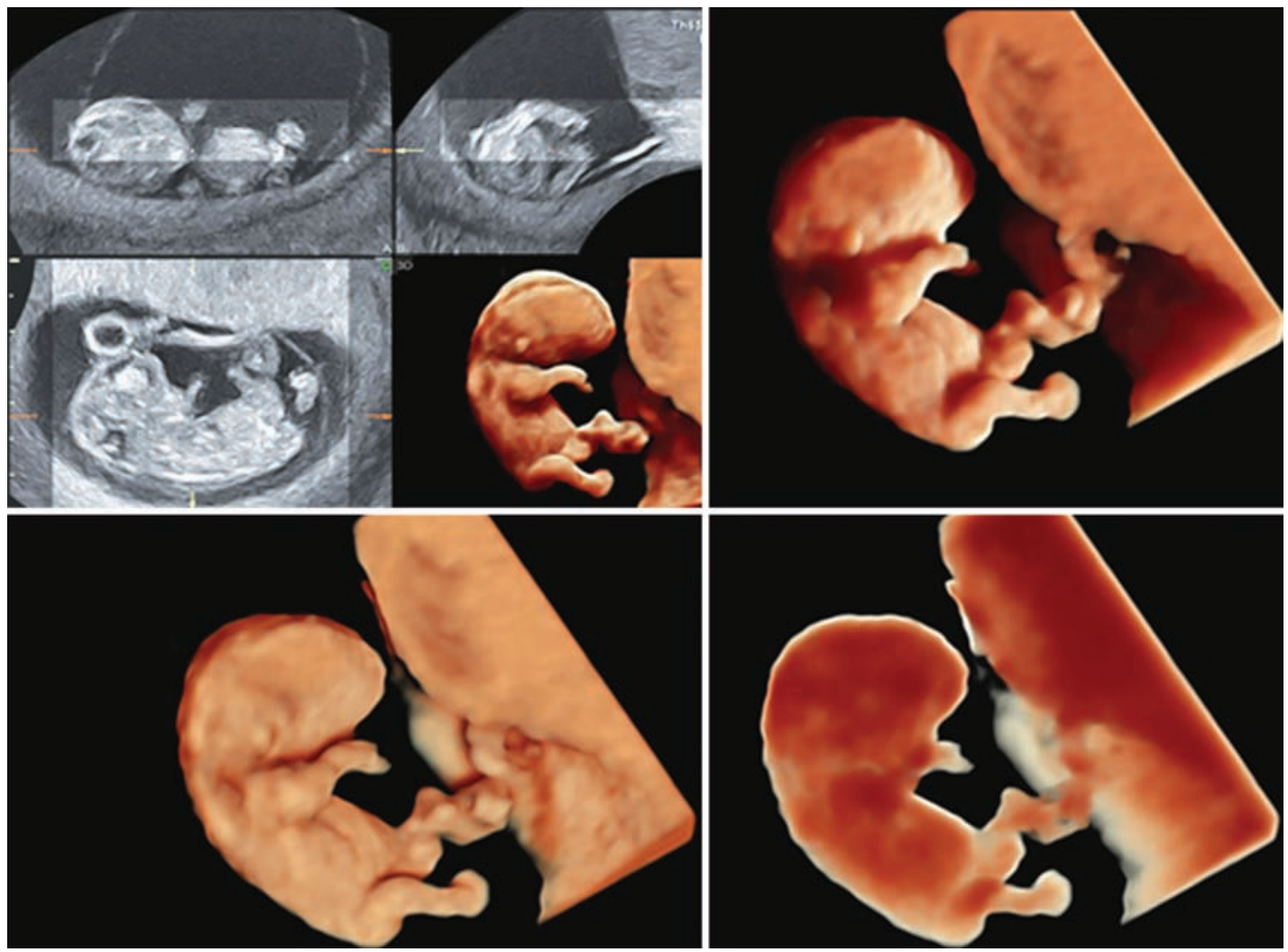

Fig. 9: HDlive with and without the maximum luminescence. Orthogonal planes in 11 weeks gestation 
First Trimester

- The omphalomesenteric duct is very large and the yolk vesicle very distant. The embryo is totally included in the amniotic sac, the cord is very thick and long. It goes to the external portion of the sac where the yolk vesicle is.

- The face profile is seen.

\section{Ultrasound Visualization at 10 Weeks of Gestation}

It is characterized by the vision of concrete structures:

- The face profile, with the nose, the mouth and the orbits.

- The back, the abdomen with the physiological herniation, the limb buds.

- In the cord, twists can be appreciated (Fig. 8).

\section{Ultrasound Visualization at 11 Weeks of Gestation}

- All the face profile, included the outline of the ears, can be seen.

- The physiological herniation disappears.

- In the members, hands, feet and fingers can be seen (Fig. 9).

\section{Ultrasound Visualization at 12 Weeks of Gestation}

Since this moment, the criteria for knowing exactly the gestational age are the crown-rump measurement and the progressive apparition of specific structures such as kidneys, liver, etc.
The cranial pole has all the scalp formed. In its inner lateral ventricles, choroid plexus and fully formed septum lucidum are seen.

\section{Ultrasound Visualization at 13 Weeks of Gestation}

We will show from this week to the end, isolated cases of pregnancies of different ages. The reader can see the beauty of the images that are achieved. Figure 10 shows a 13 week gestation.

\section{HDlive View of a Late Gestation}

We conclude these series of pictures which are shown in Figure 11, a more advanced gestation, in order to see the quality of images that are obtained and to compare them with 3D US (which is also spectacular but less demonstrative).

\section{PATHOLOGICAL FINDINGS}

\section{Introduction}

Vaginal 2D US is the gold standard technology in which first trimester diagnosis of fetal malformations is based.
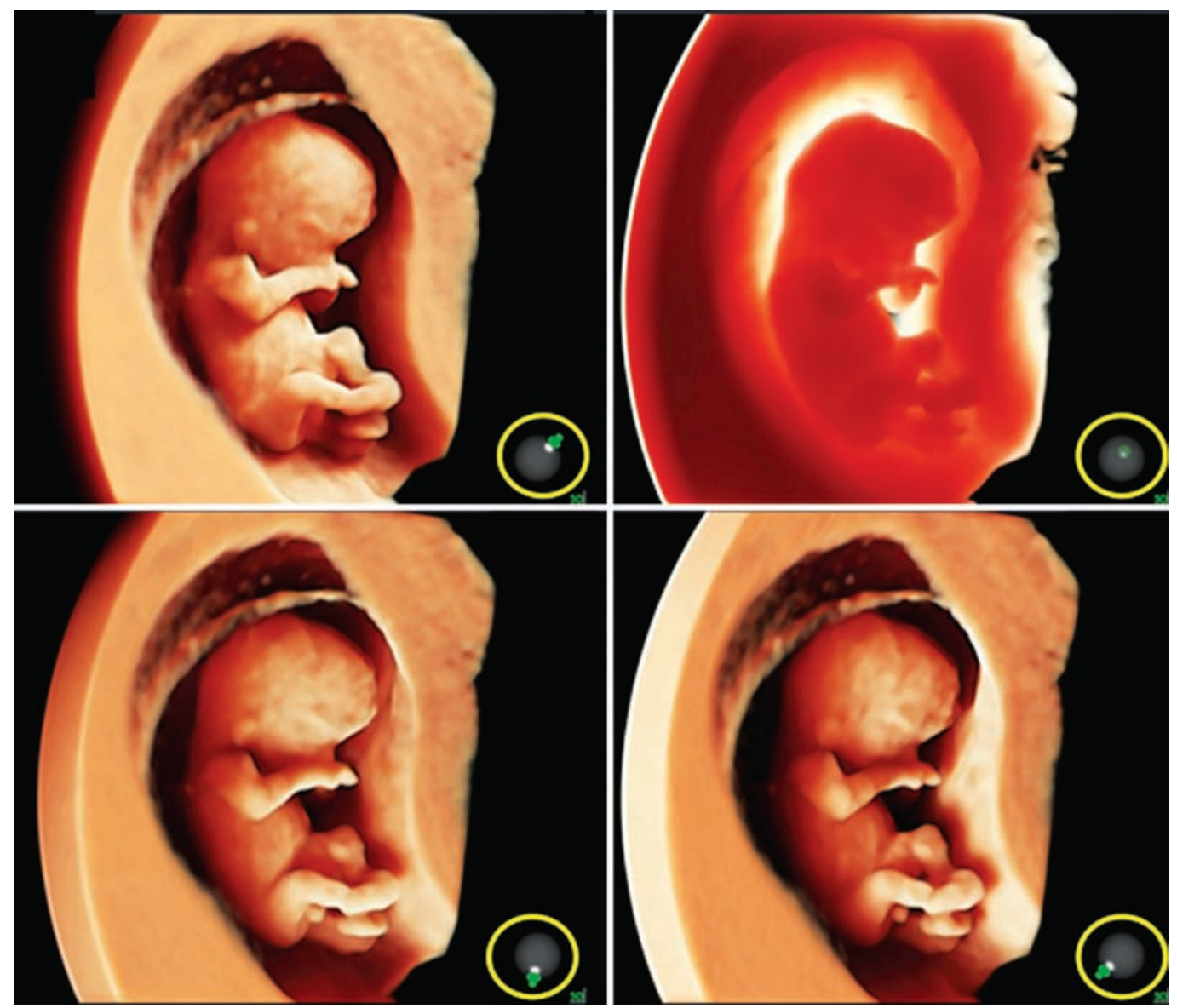

Fig. 10: Three-dimensional and HDlive. The same light source but with different fetal positions. Sometimes the legs are flexed, other ones are extended 

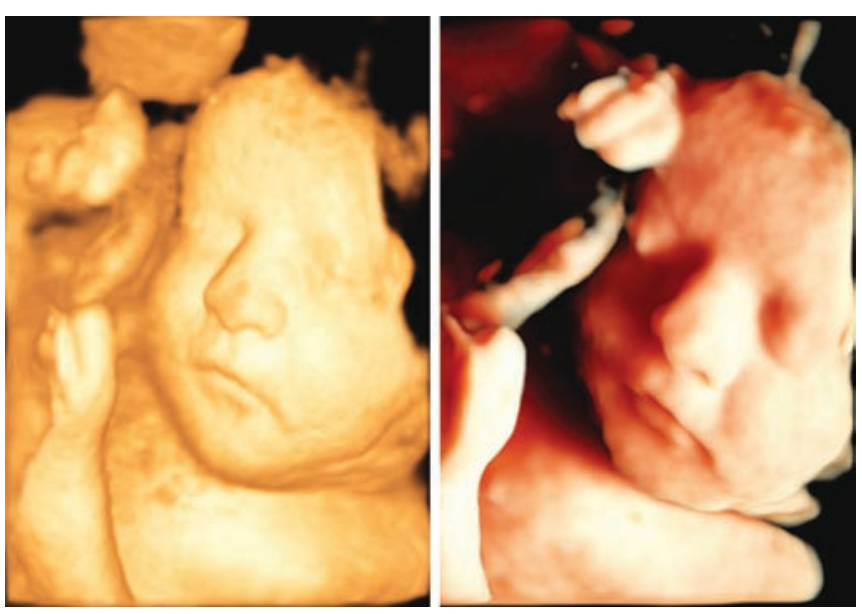

Fig. 11: We show 3D and HDlive planes from the same fetus. They are very beautiful, as if we were seeing the fetus in a video play

Over the past decades, many efforts to improve 2D ultrasound image quality have been made, but except for the switch from abdominal to vaginal route (with higher frequencies introduced during the early 1980s), there has been practically no substantial advances. HDlive produces selective illumination with its respective shadows that result in spectacular images which are much more real than those obtained with conventional 3D US.
We present some isolated cases of embryonic and adnexal malformations in order to show the beauty of the picture quality.

\section{Cases}

\section{Hygroma Colli (Fig. 12)}

We show a characteristic case of $45 \mathrm{X}$ Turner Syndrome, showing numerous and typical hygromas around the neck, head and dorsum (blue arrows). Although hygromas can be clearly seen by 2D US, HDlive images are really exceptional and shocking (Fig. 12, right side).

\section{Omphalocele (Fig. 13)}

A twin pregnancy of 16 weeks. One fetus is normal and the other one is affected by trisomy 18 . This one shows evident hand anomalies besides an abdominal tumor. Color Doppler shows the abdominal tumor containing only the liver.

\section{Too Big Yolk Sac (Fig. 14)}

We show a 6 weeks pregnancy with a too big yolk sac. We show four figures which clearly show that the yolk sac is

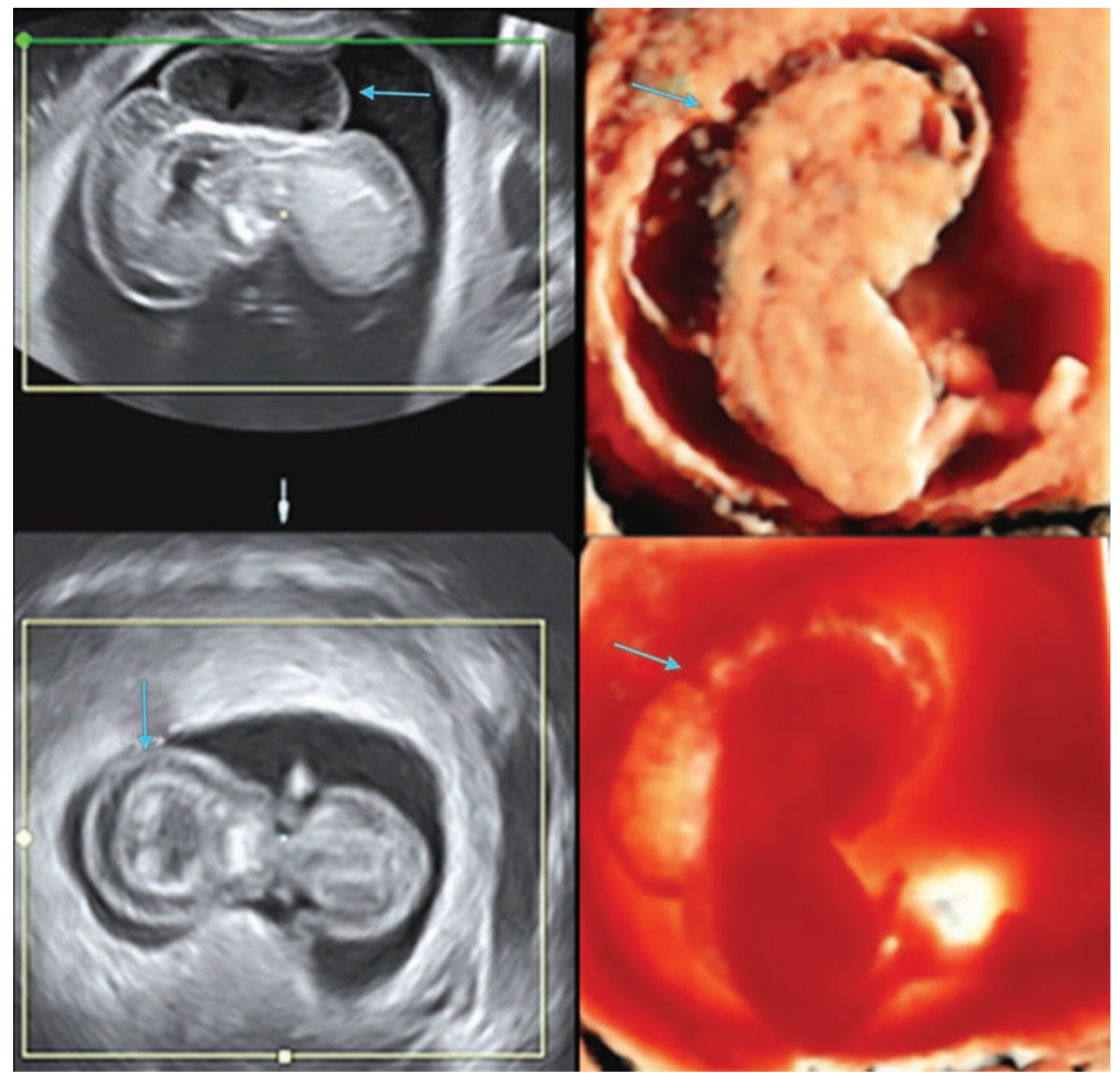

Fig. 12: Hygroma Colli in a Turner syndrome. Comparative ultrasonographic view. Left row 2D US

Upper right: Conventional 3D US. Bottom right: HDlive in maximum luminescence. The blue arrow indicates the hygroma 

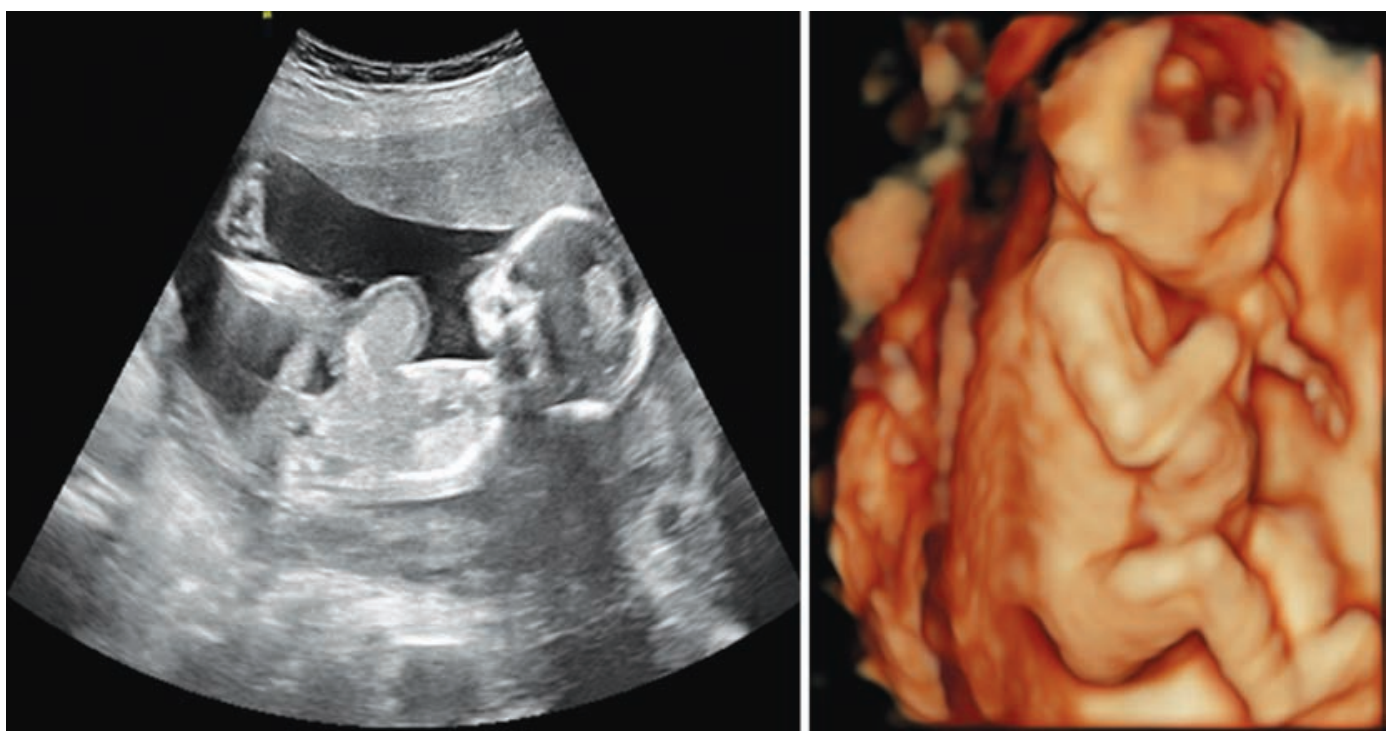

Fig. 13: 2D, 3D and HDlive of an omphalocele in a fetus with Turner syndrome. Although the 3D image has an excellent quality, the definition obtained with HDlive is really spectacular
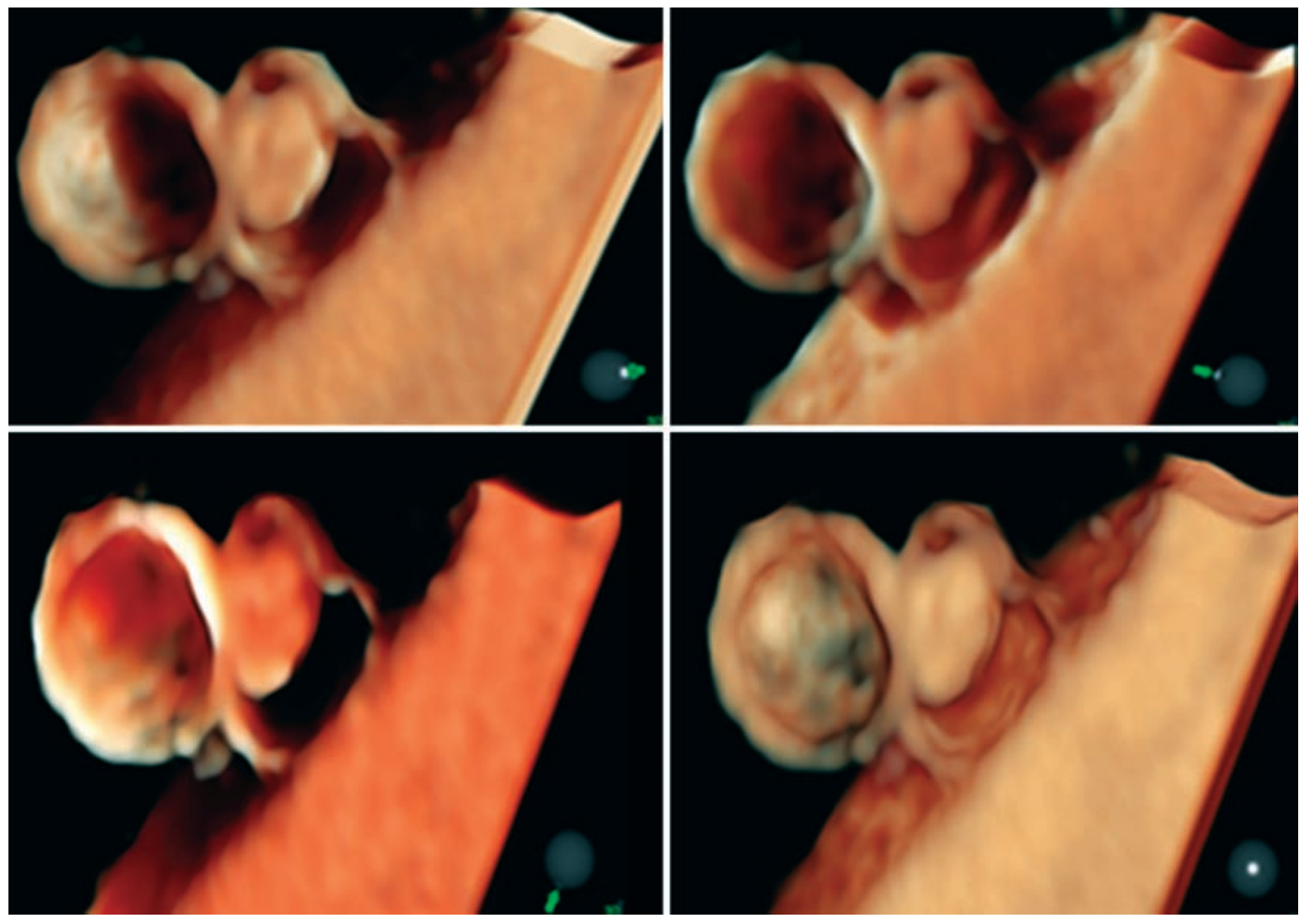

Fig. 14: A case of a too big yolk sac

extremely big, bigger than the embryo and the amniotic sac. The embryo is clearly depicted at the right (Fig. 14), below the yolk sac.

\section{Umbilical Cord Cyst (Fig. 15)}

This figure shows a small umbilical cord cyst. This cyst location, in the middle of the umbilical cord, is the most frequent one. Most of them are normal cases without chromosomal anomalies. They are frequently unique, small, round, located in the middle of the cord and they disappear in week 12.
Twin Pregnancy with a Vanishing Fetus (Fig. 16)

We show a twin pregnancy after assisted reproduction. One of the embryos has a normal evolution, but the other one, which is died, is being reabsorbed.

\section{Caudal Regression Syndrome (Fig. 17)}

Caudal regression is a rare syndrome which has a big spectrum of congenital malformations, ranging from simple anal atresia to absence of sacral, lumbar and possibly lower thoracic vertebrae. It results from a disturbance in the fetal 


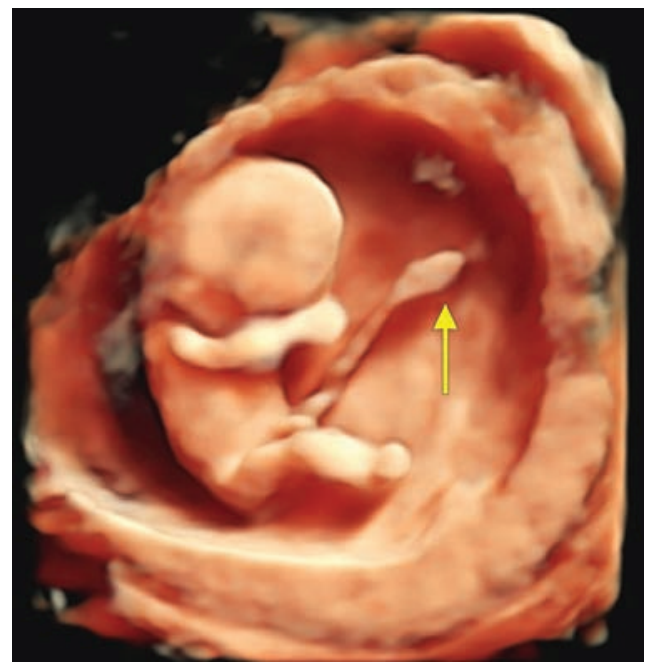

Fig. 15: Small umbilical cord cyst

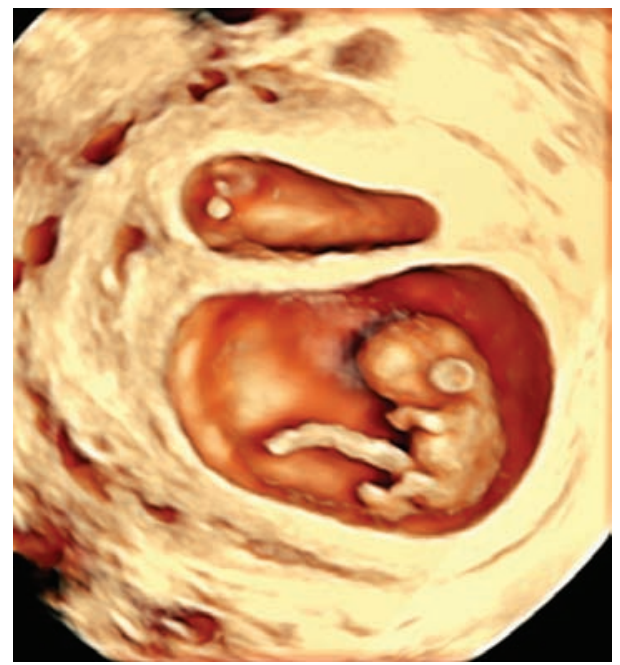

Fig. 16: Twin pregnancy, one of the sacs is very small and the embryo is being reabsorbed
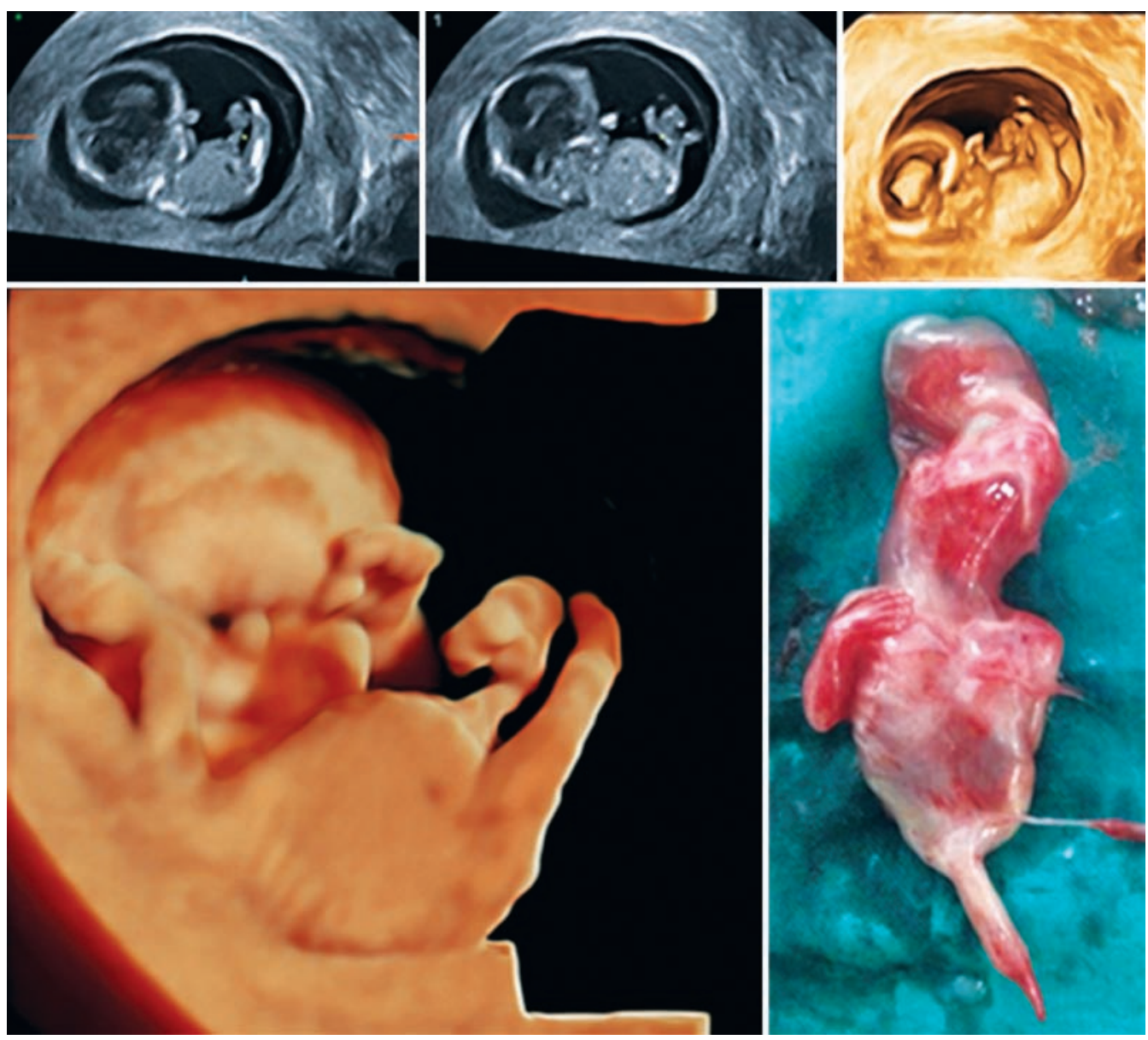

Fig. 17: 2D/3D/HDlive and macroscopic view of the syndrome

mesoderm in early pregnancy ( $<4$ th week of gestation). Maternal diabetes, genetic predisposition and vascular hypoperfusion have been suggested as possible causal factors, but no a true causal factor has been determined. Associated organ system dysfunction depends on the severity of the disease. Prenatal ultrasonographic diagnosis of this syndrome is possible at the beginning of the second trimester weeks of gestation. We report a case with 13 weeks.

\section{DISCUSSION}

Image quality is extremely important to define not only the origin, but also the nature and the extension of fetal malformations in cases of early diagnosis..$^{10-13,19-22}$

Publications focused only in obstetrics have shown that HDlive provides a much more natural and realistic appearance of the normal and malformed fetus ${ }^{10-14,19-23}$ including siamese twins. ${ }^{19}$ 
The present article shows similar images like to those ones depicted by Japanese authors. ${ }^{10-14}$ Our images are very interesting, because apart from being beautiful, they may be useful in helping patients to understand the fetal malformations, increasing patient-physician communication.

Although its capability needs to be further explored, HDlive technique represents in our opinion, a very useful that provides a realistic anatomical visualization of embryo and fetal surfaces. The complete potential of this new technology is not already revealed, and we believe that its clinical use may go beyond the gynecological field.

\section{REFERENCES}

1. Bonilla-Musoles F. Atlas de Ecografia Obstetrica. Jims Ed. Barcelona. 1982. p. 230. ISBN: 84-7092-248-3.

2. Bonilla-Musoles F, Raga F, Machado L, Bonilla J Jr, Coelho F, Sanz M, Castillo JC, Dolz M. Nuevas aplicaciones en el diagnóstico ecográfico 3D/4D en malformaciones fetales. Prog Obstet Ginecol 2008;51(10):610-618.

3. Bhaduri M, Fong K, Toi A, Tomlinson G, Okun N. Foetal anatomic survey using three-dimensional ultrasound in conjunction with first-trimester nuchal translucency screening. Prenat Diagn 2010; 30(3):267-273.

4. Clementschitsch G, Hasenöhrl G, Steiner H, Staudach A. Frühe Diagnose einer fetalen Skelettdisplasie in Assoziation mit erhörter Nackentransparenz mittels 2D- und 3D- Ultraschall. Ultraschall Med 2003;24(5):349-352.

5. Kurjak A, Kupesic S, Ivancic-Kosuta M. Three-dimensional transvaginal ultrasound improves measurement of nuchal translucency. J Perinat Med 1999;27(2):97-102.

6. Shaw SW, Hsieh TT, Hsu JJ, Lee CL, Cheng PJ. Measurement of nuchal volume in the first trimester Down screening using three-dimensional ultrasound. Prenat Diagn 2009;29(1):69-73.

7. Snijders RJ, Noble P, Sebire N, Souka A, Nicolaides KH. UK multicentre Project on assessment of risk of trisomy 21 by maternal age and fetal nuchal-translucency thickness at 10-14 weeks of gestation. Foetal Medicine Foundation First trimester Screening Group. Lancet 1998;352(9125):343-346.

8. Kagan KO, Pintoffl K, Hoopmann M. First-trimester ultrasound images using HDlive. Ultrasound Obstet Gynecol 2011;38(4):607.

9. Merz E. Oberflächendarstellung eines Feten $(28+2$ SSW) mittels HDlive Technologie. Ultraschall Med 2012;33(3):211-212.
10. Hata T, Tenkumo C, Sato M, Kanenishi K, Ishimura M. Three-dimensional HDlive rendered images of intrauterine abnor-malities during pregnancy. J Med Ultrasonics (Japan) 2013;40(2):179-180.

11. Grigore M, Mares A. The role of HDlive technology in improving the quality of obstetrical images. Med Ultrason 2013;15(3): 209-214.

. 12. Hata T, Hanaoka U, Tenkumo C, Sato M, Tanaka H, Ishimara M. Three- and four dimensional HDlive rendering images of normal and abnormal fetuses: pictorial assay. Arch Gynecol Obstet 2012; 286(6):1431-1435.

13. Hata T, Hanaoka U, Mashima M. HDlive rendering image of cyclopia and proboscis in a fetus with normal chromosomes at 32 weeks of gestation. J Med Ultrasonics 2014;41(1):109-110.

14. Hata T, Sato M, Kanenishi K, et al. 4D sonography in assessment of fetal neurobehavior. Donal School J Ultrasound Obstet Gynecol 2012;6(2):121-131.

15. Hata T, Hanaoka U, Mashima M, Ishimara M, Marumo G, Kanenishi K. Four-dimensional HDlive rendering image of fetal facial expression. A pictorial assay. J Med Ultrasonics 2013;40(4): 437-441.

16. Sato M, Kanenishi K, Hanaoka U, Noguchi J, Marumo G, Hata T. 4D ultrasound study of fetal facial expressions at 20 to 24weeks of gestation. Int J Gynaecol Obstet 2014;126(3):275-279.

17. Kanenishi K, Hanaoka U, Noguchi J, Marumo G, Hata T: 4D Ultrasound evaluation of fetal facial expressions during the latter stages of the second trimester. Internat J Gynecol Obstet 2013; 121(3):257-260.

18. Hata T. HDlive rendering image at 6 weeks of gestation. J Med Ultrasonics 2013;40(4):495-496.

19. Merz E. 3D Darstellung von Siamesischer Zwillingen mit 12+3 Schwangerschaftswochen. Ultraschall Med 2013;34(2):109-111.

20. Bonilla-Musoles F, Raga F, Castillo JC, Bonilla Jr F, Climent MT , Caballero O. High definition real time ultrasound (HDlive) of embryonic and fetal malformations before week 16. Donald School J Ultrasound Obstet Gynecol 2012;7(1):1-8.

21. Bonilla-Musoles F, Raga F, Castillo JC, Bonilla Jr F, Caballero O. Revisión Alta definición Ecografica en tiempo real (HDlive US) en Obstetricia y Ginecologia. Rev Peru Ginecol Obstet 2013;59(1):33-41.

22. Bonilla-Musoles F, Raga F, Osborne N, Bonilla F Jr, Castillo JC, Caballero O. Pictorial review. Multimodality 3D volumetric ultrasound in Obstetrics and Gynaecology with an emphasis in HDlive technique. Ultrasound Quarterly 2013;29(3):189-201.

23. Tanaka T, Ito M, Uketa E, Mori N, Hanaoka U, Kanenishi K, Tanaka $\mathrm{H}$, Hata T. Antenatal three-dimensional sonographic features of multicystic kidney. J Med Ultrasonics 2013;40(2):181-183. 